\title{
Biorefinery concept for discarded potatoes: Recovery of starch and bioactive compounds
}

\author{
M.D. Torres ${ }^{\text {a, }}$, P. Fradinho ${ }^{\text {a,b }}$, P. Rodríguez ${ }^{\text {a }}$, E. Falque ${ }^{c}$, V. Santos ${ }^{\text {a }}$, H. Domínguez ${ }^{\text {a }}$ \\ ${ }^{a}$ Department of Chemical Engineering, Faculty of Sciences, Universidade de Vigo, As Lagoas, 32004, Ourense, Spain \\ ${ }^{\mathrm{b}}$ Instituto Superior de Agronomia, Universidade de Lisboa, Tapada da Ajuda, 1349-017, Lisbon, Portugal

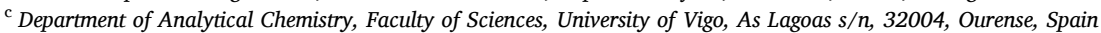

\section{A R T I C L E I N F O}

\section{Keywords:}

Autohydrolysis

Bioactives

Foodstuff hydrogels

Skin

Flesh

Starch

Waste

\begin{abstract}
A B S T R A C T
The integral valorisation of discarding potatoes from three local varieties using processes of low environmental impact to recover the starch contained in the flesh as well as the bioactive compounds present in the skin or in the processing wastewaters was studied. The remaining flesh after starch extraction was also recovered to further processing. The extraction of starch and active extracts using environmentally friendly technologies, the physicochemical and phytochemical characterisation of the extracts, the formulation and mechanical characterisation of the corresponding functional hydrogels, have allowed proposing potential food and non-food applications. Results indicated that subcritical water extraction $(220 \mathrm{C})$ was an efficient technology to recover antioxidants from the potato skin. Processing wastewaters exhibited high protein content. The extracted starch featured comparable physicochemical properties to that available commercially and the corresponding hydrogels exhibited enhanced mechanical properties with absence of syneresis. It should be remarked that Agria and Neiker varieties provided the highest total starch and bioactive content in terms of phenolics, TEAC value and DPPH inhibition percentage, respectively.
\end{abstract}

\section{Introduction}

Potato is the world's fourth largest food crop with an estimated production of 388 million tonnes in 2017 , led by Asia with over $50.4 \%$ of the world total and followed by Europe (31.5\%), America (11.4\%), Africa (6.4\%) and Oceania (0.6\%) (FAOSTAT, 2017). The major species grown worldwide is Solanum tuberosum, and modern varieties of this species are the most widely consumed (Bzducha-Wrobel et al., 2015). During the harvest and storage of this edible perishable tuber a high degree of discarding (up to $30 \%$ ) is generated, since they do not meet the size, quality, colour or suffer from plagues, and currently has a low added value being used primarily for animal feed (Priedniece et al., 2017). Another massive wastes from the potato processing industry are the peels and outer flesh layers as well as flesh or wastewaters remaining from the starch extraction, where important amounts of gelling or bioactive fractions are contained and could be easily recovered (Gientka et al., 2019). Losses produced from potatoes peeling can represent up to $40 \%$ depending on the procedure used (Pathak et al., 2018); whereas those from the flesh after the starch processing in industry can account for $75 \%$ of initial product mass (Ahmed et al., 2018) and the corresponding wastewaters represented about 10.8 million $\mathrm{m}^{3}$ in 2017 (Dupuis and Liu, 2019). Consequently, the valorisation of these wastes containing high valuable compounds (starch, protein, antioxidants or fibre, among others) is a real need that could be of relevance to the potato industry helping to improve the economical balance of the industrial process and to commercialize new products (Priedniece et al., 2017; Nazarian-Firouzabadi and Visser, 2017).

The functional properties of the potato recovered components highly depend on the extraction procedure. In the case of mild extraction procedures, the obtained potato proteins are highly soluble and exhibit remarkable foaming and emulsifying characteristics. These methods also allow to recovery fibers that can lead to development of a threedimensional network in the end-product which impressively improve the texture and stability of the matrix (Priedniece et al., 2017). An alternative with great potential is the recovery of biopolymer compounds with gelling properties as the starch required to alleviate the growing market of biopolymer-based hydrogels with food and non-food applications (Torres et al., 2018). As well as, bioactive extracts with antioxidant, anti-inflammatory, antimicrobial or antitumor properties (Friedman et al., 2017), present in potatoes, using extraction techniques

\footnotetext{
* Corresponding author.

E-mail address: matorres@uvigo.es (M.D. Torres).
} 
based on so-called clean technologies as subcritical water extraction, following the current trends in green chemistry, using water as the only extraction agent (Gonzalez et al., 2017). Briefly, subcritical water extraction is a pressurized hot water extraction, which is also called high-temperature water extraction or autohydrolysis. As it is well-known, this technique consist in applying high temperature and pressure in the subcritical water region, between the boiling temperature at normal conditions $(100 \mathrm{C})$ and the critical point $(374 \mathrm{C})$. In this reaction medium, the biopolymers can react with high conversion rates and in very short residence times (Burnner, 2009). Some recent studies can be found in the literature on the valorisation of the potato disposals (see as e.g. Sepelev and Galoburda, 2015; Nazarian-Firouzabadi and Visser, 2017; Pathak et al., 2018), but a comprehensive research on the integral valorisation as proposed here has not been reported yet.

Hydrogels from starch are the most available and economic materials. The incorporation of functional components in formulations with high starch content and bioactive compounds is a growing trend for food and non-food applications (Witczak et al., 2015). An intense search for new renewable sources to produce natural biopolymers for edible coatings or biodegradable films is observed as they offer lower environmental costs (Larotonda et al., 2016). In addition, other sectors, such as biomedical, pharmaceutical and cosmetic, increasingly use compounds with high bioactivity extracted from natural sources (Liu et al., 2015). The future of biopolymer materials is to show that vegetable materials from natural, under-utilized and renewable sources can overcome their traditional counterparts based on oil. These biopolymers recently gained attention for emerging manufacturing technologies such as $3 \mathrm{D}$ printing, since it is much easier to work with them during processing, they are compatible for use in food, pharmacy or cosmetics, non-toxic and smell-free (Jonathan and Karim, 2016). The knowledge of the thermomechanical behaviour during the formulation of starchy-based gels provides relevant information to select the optimum processing conditions to achieve well-defined and tailor-made final products, especially for hydrogels from extracts from disposal sources (Torres et al., 2018). This developing market has enormous potential to improve the welfare of the population.

In this context, the main aim of this work is the integral valorisation of discarded potatoes from different local varieties using sustainable approaches based on the biorefinery concept for potential food and nonfood applications. For this purpose, the extraction of biopolymer and bioactive compounds using environmentally friendly technologies is proposed. The physicochemical and phytochemical characterisation of the extracts and the mechanical properties of the corresponding functional hydrogels are studied.

\section{Materials and methods}

\subsection{Raw materials}

Low-sized or irregular shape discarded potatoes from three varieties (i.e. Agria, Kennebec and Neiker) harvested in Galicia (Spain), were kindly provided by the Instituto Ourensan de Desenvolvemento Economico (INORDE). Above varieties were selected based on their potential high content of starch and bioactive compounds, when compared with other local varieties. Commercial potato starch (CAS: 9005-84-9, Scharlau, Spain) was also used as raw material with comparative purposes.

\subsection{Extraction of high valuable compounds}

\subsubsection{Starch}

The starch extraction conditions (i.e. water ratios, samples sizes, mixing times, sieve size, among others) were optimised for the potato samples using only water as extraction reagent to increase the starch yield and purity. The employed procedure was based on the conventional extraction process used for the industrial potato starch extraction (Wu, 2016). Concisely, the proposed method to extract starch from discarding potatoes consisted of several sequential steps: (i) manual peeling of potatoes; (ii) cutting and milling the flesh; (iii) adding water (solid:liquid ratio, 1: 2), (iv) mixing the milled flesh with water (60 min, $200 \mathrm{rpm})$ and $(\mathrm{v})$ filtering with a sieve $(80 \mu \mathrm{m})$, separating the flesh from the liquid filtrate. After this, (vi) washing the flesh to drag the remaining starch; (vii) leave overnight the filtrate and washing water in the fridge $24 \mathrm{~h}$ to promote the starch decantation and (viii) separate the starch from filtering and washing waters. Then, (ix) drying the starch in an air drying convective oven at $40 \mathrm{C}$ for $48 \mathrm{~h}$ and $(\mathrm{x})$ homogenizing the moisture content of the starch placing the samples in petri dishes in a desiccator containing $\mathrm{MgCl}_{2}$ for about one week until constant weight. Finally, (xi) storing of the starch in closed plastic boats at room temperature and storing of processing wastewaters and remaining flesh after starch extraction in jars in the freezer ( $20 \mathrm{C})$ until further analysis.

\subsubsection{Bioactive fractions}

In order to recover the bioactive fractions, the coarse milled potato skin $(0.25-2 \mathrm{~mm})$ was subjected to subcritical water extraction. Initially, a temperature sweep between 120 and $220 \mathrm{C}$ was performed with the most bioactive potato variety to select the autohydrolysis conditions. Then, the milled skin was contacted with water (solid:liquid ratio, 1:15), the aqueous suspension was stirred and heated up to selected temperature $(220$ C) in a pressurized reactor (Parr Instruments series 4848, Illinois, USA). The liquid fraction was separated by filtration and was stored in a fridge ( 4 C) until further phytochemical analysis. In all cases, analyses were performed before a week.

\subsection{Physicochemical characterisation}

\subsubsection{Composition}

Moisture content was determined according to the standard gravimetric method, 925.10 (AOAC, 2000). Ash amount was obtained after calcination in a muffle for $6 \mathrm{~h}$ at 575 C. Total starch and amylose content were calculated using two enzymatic kits (Megazyme, Co., Wicklow, Ireland) following standard procedures (AACC, 2010). Protein content was quantified by Kjeldahl method using a Flash EA 1112 Elemental Analyser (Thermo Fisher Scientific, MA, USA) with the nitrogen conversion factor of 6.25 (Torres et al., 2019). Na and $\mathrm{K}$ content was determined by atomic emission spectrophotometry; whereas $\mathrm{Ca}^{2}, \mathrm{Mg}^{2}$ and $\mathrm{Fe}^{2}$ content was obtained by atomic absorption spectrophotometry. In both cases, minerals experiments were conducted on a 220 Fast Sequential Spectrophotometer (Varian, NY, USA). Previously, a pre-treatment of the samples consisting of an acid digestion with $\mathrm{HNO}_{3}$ in a microwave (Marsxpress-CEM Co., NY, USA) operating at $1.6 \mathrm{KW}$ for $15 \mathrm{~min}$ followed by $200 \mathrm{C}$ for $10 \mathrm{~min}$ was necessary in this work, following the conditions detailed by Florez-Fernandez et al. (2019). Carbohydrates determination was carried out by High Performance Liquid Chromatography, using a 1200 series Hewlett-Packard chromatograph with a refractive index (RI) detector, as reported elsewhere (e.g. Florez-Fernandez et al., 2019). In order to determine the fraction of carbohydrates, aliquots of liquors obtained at different temperatures during the autohydrolysis treatment were analysed by HPLC-RI (Aminex HPX-87H, BioRad, Hercules, USA). Note here that a previous filtration through $0.45 \mu \mathrm{m}$ cellulose acetate membranes was made. Saccharide fractions were determined by means of a $300 \quad 7.8$ mm Aminex HPX-87H column (BioRad, Hercules, USA). The operating conditions were $5 \mathrm{~N} \mathrm{H}_{2} \mathrm{SO}_{4}, 0.6 \mathrm{~mL} / \mathrm{min}$ and $50 \mathrm{C}$. The samples were also subjected to posthydrolysis with $4 \%$ sulphuric acid in autoclave at $121 \mathrm{C}$ for $20 \mathrm{~min}$ and then were cooled down at room temperature. Posthydrolysis was made to hydrolyse the oligomers and to evaluate the content of oligomers in liquors by difference between the content of monomers in the posthydrolysis liquor and in the autohydrolysis liquor.

\subsubsection{Size measurements}

The average size/weight of the used potatoes (25 samples per variety) was determined using a calibre and an analytical balance, 
respectively. The weight-average particle diameters $\left(D_{w}\right)$ of the extracted starches were obtained according to standard sieving procedures (ASAE Standards, 1995).

\subsubsection{Colour measurements}

Colour trials were conducted on a Minolta CR-400 (Japan) tristimulus colorimeter and expressed in the CIELab system ( $\mathrm{L}^{*}, \mathrm{a}^{*}$ and $\left.\mathrm{b}^{*}\right)$. It should be indicated that $L^{*}$ defines the lightness (whiteness, $L^{*} 0$, brightness, $L^{*}$ 100), a* (degree of greenness, $a^{*}<0$, or redness, $a^{*}>$ 0 ) and $b^{*}$ (degree of blueness, $b^{*}<0$, or yellowness, $b^{*}>0$ ) are the chromaticity responsible parameters. All samples were measured at room temperature under the same light conditions at least ten times.

\subsection{Phytochemical characterisation}

Total phenolic content was analysed by the Folin-Ciocalteu method using gallic acid as standard (Singleton and Rossi, 1965). Liquors from autohydrolysis or processing wastewaters $(0.5 \mathrm{~mL})$ were mixed with distilled water $(3.75 \mathrm{~mL})$, Folin-Ciocalteu's phenol reagent $(0.25 \mathrm{~mL})$ and sodium carbonate $(0.25 \mathrm{~mL}, 10 \%, \mathrm{w} / \mathrm{v})$. Samples were incubated in darkness at room temperature for $1 \mathrm{~h}$, before absorbance measurements $(765 \mathrm{~nm}$ ) in an Evolution $201 \mathrm{UV}-\mathrm{Vis}$ spectrophotometer (Thermo Scientific, Illinois, USA).

The ABTS radical [2,2-azinobis(3-ethyl-benzothiazoline-6sulfonate)] scavenging was expressed as TEAC value (Trolox equivalent antioxidant capacity) (Re et al., 1999). A mixture of diluted ABTS solution $(1.0 \mathrm{~mL})$ and above liquor fractions $(10 \mu \mathrm{L})$ were analysed at 37 $\mathrm{C}$ for $6 \mathrm{~min}$ recording the absorbance at $734 \mathrm{~nm}$.

The antiradical capacity against the $\alpha, \alpha$-diphenyl-b-picrylhydrazyl $(\mathrm{DPPH})$ radical was also measured. In this case, liquor fractions $(50 \mu \mathrm{L})$ were mixed with the DPPH radical solution ( $2 \mathrm{~mL}$ ). After $16 \mathrm{~min}$, the decrease in absorbance $(515 \mathrm{~nm})$ was measured. The percentage perceptual absorbance reduction regarding the initial value was used to calculate the inhibition percentage.

\subsection{Preparation of the hydrogels}

Hydrogels from commercial and extracted potato starches were formulated in a wide range of biopolymer content (15-30\%, w/w) and gelling temperatures (60-90 C). Functional hydrogels were also prepared with selected starches using as solvent the autohydrolysis liquor with the most adequate bioactive features. Note here that processing conditions were selected based on the conditions previously optimised for commercial potato starches (Torres et al., 2018). In all cases, starches were dispersed in distilled water or selected liquor using cylindrical flasks (5 cm height and $12.5 \mathrm{~cm}$ diameter) and were stirred at $3000 \mathrm{rpm}$ for $10 \mathrm{~min}$ at $25 \mathrm{C}$. For rheological testing, the dispersions were directly placed into the measuring system. In contrast, for textural assays, the above dispersions were immediately heated up to certain temperatures (from 60 to $90 \mathrm{C}$ ) and held for $30 \mathrm{~min}$ with stirring in a thermal bath. Afterwards, samples were cooled down at room temperature for $60 \mathrm{~min}$ and were placed in a fridge $(4 \mathrm{C})$ for $24 \mathrm{~h}$ to allow complete gels maturation before performing textural trials. Even though, hydrogels were equilibrated at room temperature for $60 \mathrm{~min}$ before textural testing.

\subsection{Mechanical measurements}

Rheological testing in terms of elastic $\left(\mathrm{G}^{\prime}\right)$ and viscous $\left(\mathrm{G}^{\prime \prime}\right)$ moduli were conducted on a stress-controlled rheometer (MCR302, Anton Paar Physica, Austria) using a plate-plate geometry ( $25 \mathrm{~mm}$ diameter and 1 $\mathrm{mm}$ gap). Starch dispersions were placed in the measuring system and the exposed edges were sealed with paraffin oil to prevent water evaporation during trials. Initially, stress sweep tests were made at different frequencies and times $(1,10 \mathrm{~Hz}-5,25,90 \mathrm{C})$ to determine the linear viscoelastic region in both dispersions (below $17 \mathrm{~Pa}$ ) and hydrogels (below $32 \mathrm{~Pa}$ ). Then, rheological testing consisted of the following fivesteps procedure: (1) temperature ramp from 25 to $90 \mathrm{C} \mathrm{(1} \mathrm{C/min,} 1 \mathrm{~Hz}$, $5 \mathrm{~Pa}$ ) to monitor the heating profile; (2) time sweep (90 C, $15 \mathrm{~min}, 5$ $\mathrm{Pa})$; (3) cooling temperature ramp from 90 to $5 \mathrm{C}(1 \mathrm{C} / \mathrm{min}, 1 \mathrm{~Hz}, 15$ $\mathrm{Pa}$ ) to evaluate the gelling profile; (4) time sweep (5 C, $30 \mathrm{~min}$ ) to allow full hydrogels maturation, and (5) frequency sweep (5 C, $15 \mathrm{~Pa}$ ) to analyse the viscoelastic features of the gel.

Textural testing was performed in a texture analyser (TA-XT2, Stable MicroSystems, UK) with a load cell of $5 \mathrm{~kg}$ by means of the texture profile analysis (TPA). Starch hydrogels were subjected to a double penetration using a cylindrical probe $\mathrm{P} / 05 \mathrm{R}(5 \mathrm{~mm}$ penetration and 2 $\mathrm{mm} / \mathrm{s}$ crosshead speed). Firmness or peak force of the first cycle, adhesiveness or negative area of the first bite and cohesiveness or ratio between the areas of both peak forces, were calculated for tested hydrogels.

The syneresis was also analysed following the procedure previously reported (Bashir et al., 2017). Hydrogels were stored in centrifuge tubes in the fridge (4 C) for two weeks. Afterwards, samples were centrifuged ( $2500 \mathrm{~g}$ for $20 \mathrm{~min}$ ) and the syneresis calculated as the percentage of water release in relation to the gel weight.

\subsection{Statistical analysis}

All above trials, both extractions and analysis, were made at least in triplicate. Statistical analysis of the experimental data was performed using RStudio (version 1.1.463 - (C) 2009-2018 RStudio, Inc.), through variance analysis (one-way ANOVA), by the Tukey test - Post Hoc Comparison at a significance level of $95 \%(p<0.05)$. All results are presented as average standard deviation.

\section{Results and discussion}

\subsection{Schematic procedure}

Fig. 1 shows an overview of the proposed processing for an integral valorisation of the discarded potatoes. For three tested varieties, the average weight of the discarded potatoes varied between 39.6 and 66.6 $\mathrm{g}$, with average sizes (major x minor axis) ranging from $4 \quad 4.5$ to $6 \quad 5$ $\mathrm{cm}$. Independently of the used variety, the flesh and peel yields were around $87.5 \quad 0.7 \%$ and $12.5 \quad 0.7 \%$, respectively. This means two important fractions for the extraction of starch and bioactive compounds.

During the flesh processing for the starch extraction, two residual streams, one liquid (wastewaters) and the other solid (processed flesh) were generated. The starch yield (\%) accounted 24.4 1.1 for Agria variety, followed by Kennebec $\left(\begin{array}{ll}22.1 & 0.8\end{array}\right)$ and Neiker $\left(\begin{array}{ll}18.5 & 1.2\end{array}\right)$. These yields were notably higher than those reported for other similar starchy materials (below 15\%) using similar conventional extraction procedures (Dupuis and Liu, 2019). A proposed challenge was to develop a pallet of hydrogels with a broad range of mechanical properties from selected starches. Concerning the waste streams, the wastewaters represented about $300 \mathrm{~mL} / 100 \mathrm{~g}$ of the initial flesh and the solid fraction of this stream accounted between 4.5 and $9.5 \%$ of the initial flesh rich in bioactive compounds. The residual solid stream containing the remaining flesh after starch extraction meant between 66.1 and $77 \%$ of the initial flesh, being the highest fraction generated in Kennebec variety. These values are consistent with those previously reported for this fraction (around 75\%) after starch extraction (Ahmed et al., 2018). An attractive proposal for the valorisation of this waste stream could be to develop a baked snack type potato flake using the remaining flesh after the starch extraction (Fig. 1), whose processing is based in a recent preliminary work (Reyniers et al., 2018) and detailed in a parallel work (Torres et al., 2019).

During the peel processing by autohydrolysis, one liquid stream rich in bioactive compounds can be separated from a waste solid stream that could have a potential use as fertilizer or adsorbent agent following the 


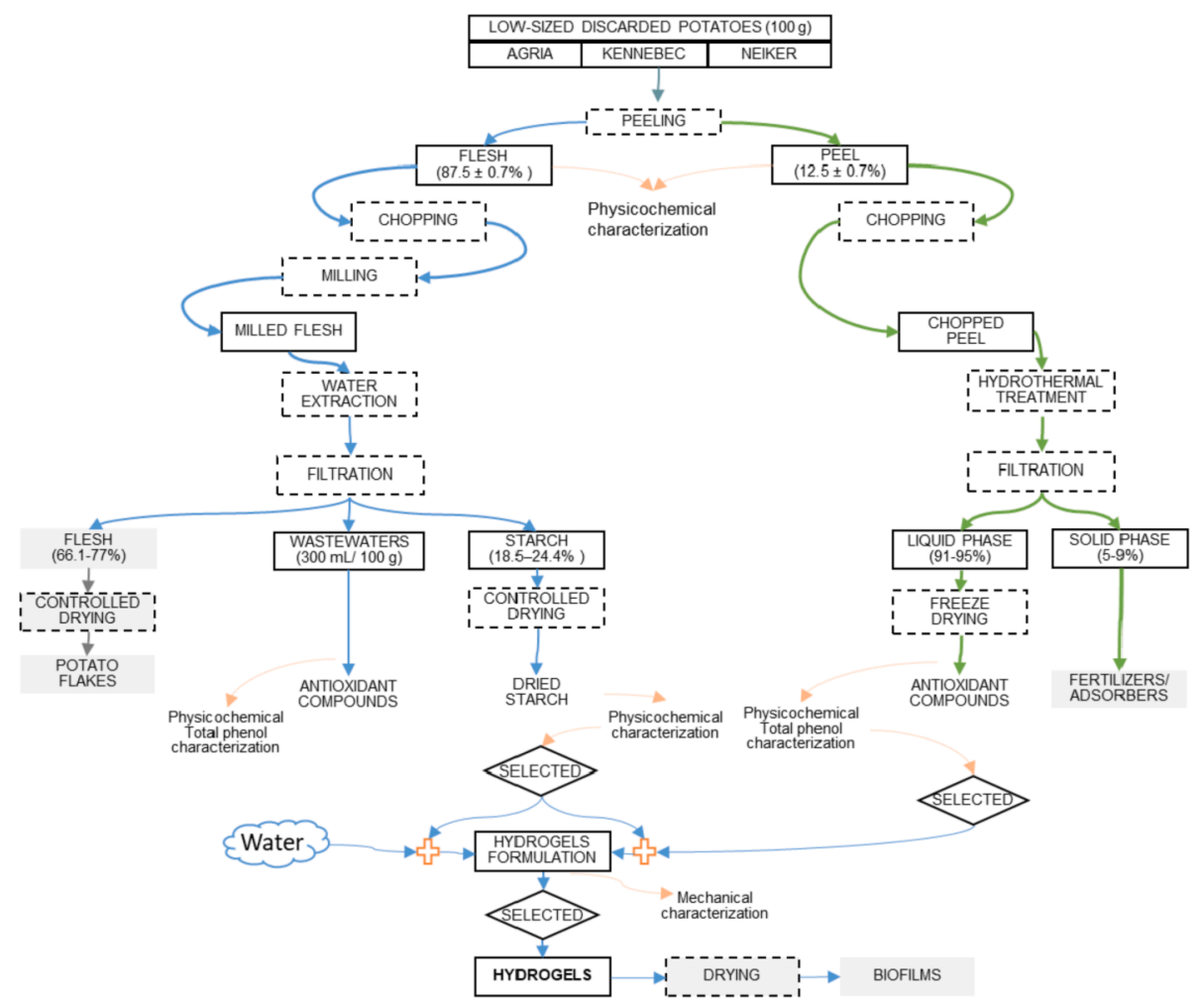

Fig. 1. Scheme of the biorefinery approach proposed for discarded potatoes. Grey symbols corresponds with processes from parallel works not detailed in this work.

physicochemical (e.g. mineral content, water sorption capacity, among others), low-cost or affinity for pollutants features stablished in previous works (De Gisi et al., 2016; Wu, 2016). The liquid stream represented around $91 \%$ of the initial peel accounting the dry weight about 5.9 $1.4 \mathrm{~g} / 100 \mathrm{~g}$. This liquid fraction could be an interesting bioactive source to prepare functional hydrogels, as it was in this work. Further processing could extend the possibilities of these hydrogels transforming them into healthy biofilms as detailed in a parallel work (Torres et al., 2019), based on the procedure reported elsewhere for other starchy materials (Larotonda et al., 2016).

\subsection{Proximate streams characterisation}

Table 1 shows fundamental physicochemical properties of the peel and flesh from the studied potato varieties. Peels from Agria exhibited the largest protein content (around $22 \mathrm{~g} / 100 \mathrm{~g}$ ), which was reduced to
$60 \%$ for Kennebec and Neiker. Fleshes presented lower protein content ( $\mathrm{g} / 100 \mathrm{~g}$ ), varying from 12.7 for Kennebec to half for Neiker variety. Even though, relevant values of this parameter were identified in all cases when compared with those reported for other varieties of potatoes (Robertson et al., 2018; de Albuquerque et al., 2019). In all cases, ashes varied in a restricted range with the lowest values observed for Neiker variety. No significant differences between Agria and Kennebec were found in this parameter. Concerning minerals, it is worth noting the content of potassium, followed by those of calcium and magnesium present both on the peel and the flesh of the three studied varieties. Kennebec variety showed the highest mineral values. High sodium values were noted in both tested fractions of this variety. From a nutritional standpoint, potatoes in general are a good source of minerals due to the cations being associated with the phosphate ester groups on potato amylopectin. As expected, tested potato varieties were rich minerals sources containing more potassium than bananas, a

Table 1

Physicochemical features of peel and flesh from the three tested potato varieties.

\begin{tabular}{|c|c|c|c|c|c|c|}
\hline \multirow[t]{2}{*}{ Components/Varieties } & \multicolumn{3}{|l|}{ Peel } & \multicolumn{3}{|l|}{ Flesh } \\
\hline & Agria & Kennebec & Neiker & Agria & Kennebec & Neiker \\
\hline Moisture (g/100 g) & $87.0 \quad 1.5^{\mathrm{a}}$ & $84.9 \quad 0.7^{\mathrm{a}}$ & $85.4 \quad 0.6^{\mathrm{a}}$ & $80.5 \quad 1.2^{\mathrm{a}}$ & $81.6 \quad 0.8^{\mathrm{a}}$ & $80.7 \quad 0.1^{\mathrm{a}}$ \\
\hline Protein $(\mathrm{g} / 100 \mathrm{~g})$ & $21.7 \quad 0.3^{\mathrm{a}}$ & $13.6 \quad 0.1^{\mathrm{b}}$ & $13.6 \quad 0.1^{\mathrm{b}}$ & $11.10 .3^{\mathrm{b}}$ & $12.7 \quad 0.4^{\mathrm{a}}$ & $6.20 .2^{c}$ \\
\hline Ash $(g / 100 \mathrm{~g})$ & $9.7 \quad 0.2^{\mathrm{a}}$ & $9.30 .1^{\mathrm{a}}$ & $8.2 \quad 0.2^{\mathrm{b}}$ & $5.2 \quad 0.2^{\mathrm{a}}$ & $5.7 \quad 0.2^{\mathrm{a}}$ & $4.2 \quad 0.1^{\mathrm{b}}$ \\
\hline \multicolumn{7}{|l|}{ Minerals (mg/kg) } \\
\hline $\mathrm{Na}$ & $14013^{c}$ & $173131^{\mathrm{a}}$ & $1812^{\mathrm{b}}$ & $759^{b}$ & $163037^{\mathrm{a}}$ & $8619^{\mathrm{b}}$ \\
\hline K & $42,305 \quad 1060^{\mathrm{b}}$ & $49089980^{a}$ & $36,803 \quad 903^{c}$ & 22,116 & $28,883 \quad 410^{a}$ & $26,886 \quad 390^{\mathrm{b}}$ \\
\hline $\mathrm{Ca}^{2}$ & $1925105^{\mathrm{b}}$ & $2462155^{\mathrm{a}}$ & $127737^{\mathrm{c}}$ & $482 \quad 7^{\mathrm{b}}$ & $53722^{\mathrm{a}}$ & $43694^{\mathrm{b}}$ \\
\hline $\mathrm{Mg}^{2}$ & \multirow{2}{*}{$\begin{array}{lr}1878 & 194^{\mathrm{b}} \\
485 & 15^{\mathrm{a}}\end{array}$} & $233678^{\mathrm{a}}$ & $149913^{\mathrm{c}}$ & $863 \quad 3^{c}$ & $132648^{\mathrm{a}}$ & $109680^{\mathrm{b}}$ \\
\hline $\mathrm{Fe}^{2}$ & & $76 \quad 4^{\mathrm{b}}$ & $642^{\mathrm{b}}$ & $241^{\mathrm{a}}$ & $<15^{\mathrm{c}}$ & $181^{\mathrm{b}}$ \\
\hline \multicolumn{7}{|l|}{ Colour ( ) } \\
\hline$L^{*}$ & $66.13 .1^{\mathrm{a}}$ & $61.5 \quad 2.7^{\mathrm{a}}$ & $48.1 \quad 1.9^{\mathrm{b}}$ & $67.2 \quad 0.4^{\mathrm{a}}$ & $64.40 .9^{\mathrm{b}}$ & 67.1 \\
\hline$a^{*}$ & $2.9 \quad 0.6^{\mathrm{b}}$ & $2.5 \quad 1.1^{\mathrm{b}}$ & $11.32 .4^{\mathrm{a}}$ & $3.5 \quad 0.2^{\mathrm{b}}$ & $0.2^{\mathrm{c}}$ & $4.4 \quad 0.2^{\mathrm{a}}$ \\
\hline$b^{*}$ & $28.1 \quad 1.6^{\mathrm{a}}$ & $28.0 \quad 2.2^{\mathrm{a}}$ & $12.8 \quad 2.2^{\mathrm{b}}$ & $25.92 .2^{\mathrm{a}}$ & $15.4 \quad 0.5^{\mathrm{b}}$ & $24.0 \quad 2.4^{\mathrm{a}}$ \\
\hline
\end{tabular}

Data are presented as mean standard deviation. Data values in a row (peel and flesh independently assessed) with different superscript letters are significantly different at the $p \quad 0.05$ level. 
well-known potassium source (Navarre et al., 2019). Regarding to colour, the largest differences in the peel were identified for the Neiker variety, whereas in the flesh were observed for Kennebec. In all cases, traditional yellow-fleshed varieties were studied with colour values in the range to those previously reported (Grudzinska et al., 2016).

Table 2 presents a comparative between the physicochemical properties of extracted starches and a commercial one. Note here that the moisture content of both commercial starch and three extracted starches was around $16.7 \quad 2.5 \%$ and the average particle size $<0.71 \mu \mathrm{m}$. These values are within those commonly used in the hydrogels preparation (Lefatle and John, 2018; Torres et al., 2018). It should be remarked that all extracted starches exhibited larger total starch content to their commercial counterparts, as well as significantly higher amylose values. The total starch content was also higher than those commonly extracted using conventional procedures (Nor Nadiha et al., 2010; Dupuis and Liu, 2019), exhibiting values usually found in the starch control (around 93\%) from commercial enzymatic kits to asses chemical starch features. This behaviour is indicative of the suitability of the proposed green extraction method to obtain high quality starches. The results suggests that the absence of chemicals and the optimisation of the solid:liquid mixing or the stirring conditions (speed rate and contact time) during the extraction procedure promoted the selective starch extraction and the dragging of unwanted components. The obtained results also suggested less content of other associated relevant components in the starch such as proteins or lipids. These differences in the chemical composition can provide starches with different functional properties, and deliver a broad range of hydrogels with different mechanical properties to those commercially available. Note here that Agria variety showed the highest percentages of total starch. Concerning protein content, the corresponding values in all isolated starches were around half of the tested commercial starch (1.6\%), except for Kennebec variety where no significant differences were found. The starch of tested potato varieties exhibited high values of potassium, even much higher than its commercial counterpart. The second position in the rank was occupied by calcium. Large sodium content was identified in the commercial starch sample. Other relevant fact, it is that extracted starches showed comparable colour parameter values to those from commercial starch, not observing significant colour differences with starch from Agria. Even though, all tested starches presented colour features in the range of those reported for this kind of material (Priedniece et al., 2017; Witczak et al., 2015).

The wastewaters resulting from the starch processing also exhibited

Table 2

Physicochemical properties of commercial potato starch used as control and extracted starches from the three discarded potatoes varieties.

\begin{tabular}{|c|c|c|c|c|c|c|c|c|}
\hline \multirow{2}{*}{$\begin{array}{l}\text { Components/ } \\
\text { Varieties } \\
\text { Moisture }(\mathrm{g} / 100 \mathrm{~g})\end{array}$} & \multicolumn{2}{|c|}{ Commercial } & \multicolumn{2}{|l|}{ Agria } & \multicolumn{2}{|c|}{ Kennebec } & \multicolumn{2}{|c|}{ Neiker } \\
\hline & 16.7 & $1.5^{\mathrm{a}}$ & 15.9 & $1.7^{\mathrm{a}}$ & 16.4 & $1.3^{\mathrm{a}}$ & 18.4 & $1.9^{\mathrm{a}}$ \\
\hline $\begin{array}{l}\text { Total starch (g/100 } \\
\text { g) }\end{array}$ & 80.0 & $1.9^{\mathrm{d}}$ & 91.2 & $0.5^{\mathrm{a}}$ & 83.4 & $0.2^{\mathrm{c}}$ & 88.6 & $0.3^{\mathrm{b}}$ \\
\hline Amylose ratio (\%) & 15.6 & $0.4^{\mathrm{d}}$ & 29.3 & $2.3^{\mathrm{a}}$ & 27.3 & $1.1^{\mathrm{b}}$ & 23.0 & $1.7^{\mathrm{c}}$ \\
\hline $\begin{array}{l}\text { Protein }(\mathrm{g} / 100 \mathrm{~g}) \\
\text { Minerals }(\mathrm{mg} / \mathrm{kg})\end{array}$ & 1.6 & $0.3^{\mathrm{a}}$ & 0.7 & $0.2^{\mathrm{b}}$ & 1.1 & $0.3^{\mathrm{a}, \mathrm{b}}$ & 0.7 & $0.2^{\mathrm{b}}$ \\
\hline $\mathrm{Na}$ & 5354 & $121^{\mathrm{a}}$ & 25.1 & $4^{\mathrm{d}}$ & 66 & $3^{c}$ & 27 & $5^{d}$ \\
\hline $\mathrm{K}$ & 175 & $13^{\mathrm{c}}$ & 688 & $32^{\mathrm{a}}$ & 1575 & $96^{\mathrm{a}}$ & $\begin{array}{l}1120 \\
101^{\mathrm{a}}\end{array}$ & \\
\hline $\mathrm{Ca}^{2}$ & 322 & $21^{\mathrm{b}}$ & $\begin{array}{l}248.5 \\
13^{\mathrm{b}}\end{array}$ & & 225 & $16^{\mathrm{b}}$ & 220 & $9^{b}$ \\
\hline $\begin{array}{l}\mathrm{Mg}^{2} \\
\mathrm{Fe}^{2}\end{array}$ & $\begin{array}{l}23.4 \\
<15\end{array}$ & $19^{\mathrm{d}}$ & $\begin{array}{l}45 \\
<15\end{array}$ & $6^{c}$ & $\begin{array}{l}54.2 \\
<15\end{array}$ & $9^{c}$ & $\begin{array}{l}42.7 \\
<15\end{array}$ & $4^{c}$ \\
\hline Colour ( ) & & & & & & & & \\
\hline $\mathrm{L}^{*}$ & 92.4 & $2.2^{\mathrm{a}}$ & 94.8 & $1.1^{\mathrm{a}}$ & 91.5 & $1.7^{\mathrm{a}}$ & 93.8 & $1.5^{\mathrm{a}}$ \\
\hline$a^{*}$ & 5.0 & $0.2^{\mathrm{a}}$ & $\begin{array}{r}5.1 \\
0.5^{\mathrm{a}}\end{array}$ & & 4.9 & $0.7^{\mathrm{a}}$ & 4.5 & $0.2^{\mathrm{a}}$ \\
\hline$b^{*}$ & 12.6 & $0.5^{\mathrm{a}}$ & 11.2 & $1.3^{\mathrm{a}}$ & 7.7 & $0.1^{\mathrm{b}}$ & 7.5 & $0.2^{\mathrm{b}}$ \\
\hline
\end{tabular}

Data are presented as mean standard deviation. Data values in a row with different superscript letters are significantly different at the $p \quad 0.05$ level. interesting features (Table 3). In all cases, it is worthy of underlining the high protein content of washing waters, with values ranging between $15.1 \%$ for the Kennebec variety and $19.2 \%$ for the Neiker variety. Note here that the majority of potato proteins are of high nutritional and biological value. Likewise, potato proteins are appreciated by their high solubility with efficient emulsification, high foaming and good gelation properties, allowing accomplish optimal texture, stability or appearance in a wide array of food applications (Peksa et al., 2009). Washing waters from the starch extraction of Neiker flesh also presented the best values in terms of bioactive compounds and the darkest colour. The obtained magnitudes are comparable with those found for other natural sources proposed as alternative bioactive sources (Liu et al., 2015; Sepelev and Galoburda, 2015). These data support the relevance of recovering high valuable fractions from these wastewaters.

Fig. 2 shows some representative features of liquid phases obtained by autohydrolysis at selected temperature $(220 \mathrm{C})$ for the peels of tested potatoes. Again, the highest values in terms of total phenolic content, antioxidant capacity or inhibition percentage were presented by Neiker variety, followed by Kennebec and Agria. These values are in the range of those found for other varieties of native potatoes, highlighting the high inhibition percentages obtained for Neiker (around 20\%) (Pathak et al., 2018; Seijo-Rodríguez et al., 2018). In all cases, the most abundant carbohydrate was glucose followed by far for xylose, being Kennebec and Agria those with the largest values of this parameter. Colour results are consistent with those trends observed in the wastewaters, exhibiting the darkest colour the samples with the highest bioactive compounds. This behaviour has been previously suggested elsewhere for different bioactive natural matrices (Wu, 2016; de Albuquerque et al., 2019).

Based on the aforementioned outcomes, it can be indicated that Agria and Neiker varieties provided the most adequate properties in terms of starch and bioactives, respectively. Neiker showed higher phenolic content, and correspondingly higher antiradical potency than other varieties. For this variety, the effective concentration at which $50 \%$ of DPPH radical was scavenged $\left(\mathrm{EC}_{50}\right)$ was around $0.11 \mathrm{~g} / 100 \mathrm{~g}$ dry weight sample, increasing up to 0.29 and $0.35 \mathrm{~g} / 100 \mathrm{~g}$ for Agria and Kennebec varieties (Fig. 2b). The total phenolic content was consistent with Silva et al. (2016), who reported values around $233 \mathrm{mg} / \mathrm{g}$ for potato peels of a different $S$. tuberosum variety as Fianna. Lower phenolic content was found for potato flesh of Agria or Kennebec (Seijo-Rodríguez et al., 2018). Consequently, starch from flesh of Agria (0.99 $\mathrm{mg} / \mathrm{g})$ and Kennebec $(0.89 \mathrm{mg} / \mathrm{g})$ bioactive compounds from peel of Neiker were selected to further insight, assessing them as potential matrices in the development of functional hydrogels.

\subsection{Technological aptitude of proposed hydrogels}

\subsubsection{Thermorheological features}

Fig. 3 shows the thermorheological behaviour of hydrogels prepared with Agria starch (15\%, $90 \mathrm{C})$, as representative of tested systems. The heating profile (Fig. 3a) of aqueous starch dispersions presented an inflection point corresponding to the initial gelatinisation temperature (around $53 \mathrm{C}$ ) and then a rapid rise of both elastic $\left(\mathrm{G}^{\prime}\right)$ and viscous $\left(\mathrm{G}^{\prime \prime}\right)$

Table 3

Characterisation of wastewaters from starch extraction.

\begin{tabular}{llllllll}
\hline Components/Varieties & Agria & \multicolumn{3}{l}{ Kennebec } & \multicolumn{3}{l}{ Neiker } \\
\hline Protein (g/100 g) & 17.1 & $0.5^{\mathrm{b}}$ & 15.1 & $0.5^{\mathrm{b}}$ & 19.2 & $0.6^{\mathrm{a}}$ \\
Folin (g/g extract) & 0.10 & $0.01^{\mathrm{b}}$ & 0.06 & $0.01^{\mathrm{c}}$ & 0.13 & $0.01^{\mathrm{a}}$ \\
TEAC (g/g extract) & 0.13 & $0.01^{\mathrm{b}}$ & 0.10 & $0.01^{\mathrm{c}}$ & 0.16 & $0.01^{\mathrm{a}}$ \\
Inhibition (\%) & 3.2 & $0.1^{\mathrm{b}}$ & 2.5 & $0.3^{\mathrm{c}}$ & 9.6 & $0.1^{\mathrm{a}}$ \\
Colour ( ) & & & & & & & \\
$\mathrm{L}^{*}$ & 22.3 & $0.8^{\mathrm{b}}$ & 29.3 & $1.6^{\mathrm{a}}$ & 18.3 & $0.9^{\mathrm{c}}$ \\
$\mathrm{a}^{*}$ & 5.8 & $0.3^{\mathrm{a}}$ & 1.4 & $0.8^{\mathrm{c}}$ & 3.1 & $0.5^{\mathrm{b}}$ \\
$\mathrm{b}^{*}$ & 3.6 & $0.7^{\mathrm{b}}$ & \multicolumn{2}{c}{1.1} & $0.2^{\mathrm{c}}$ & 5.1 & $0.7^{\mathrm{a}}$ \\
\hline
\end{tabular}

Data are presented as mean standard deviation. Data values in a row with different superscript letters are significantly different at the $p \quad 0.05$ level. 
(a)

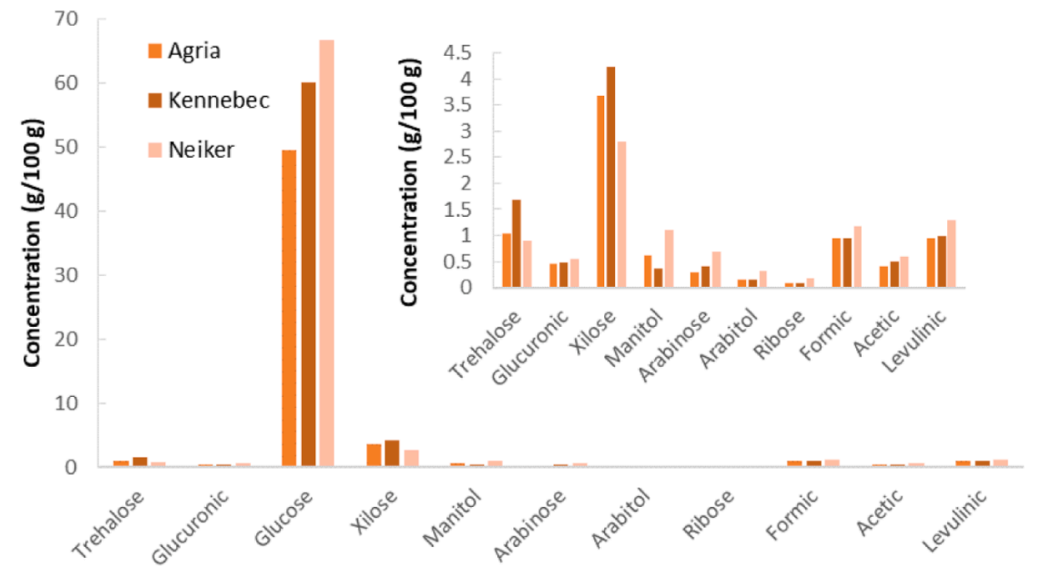

(b)

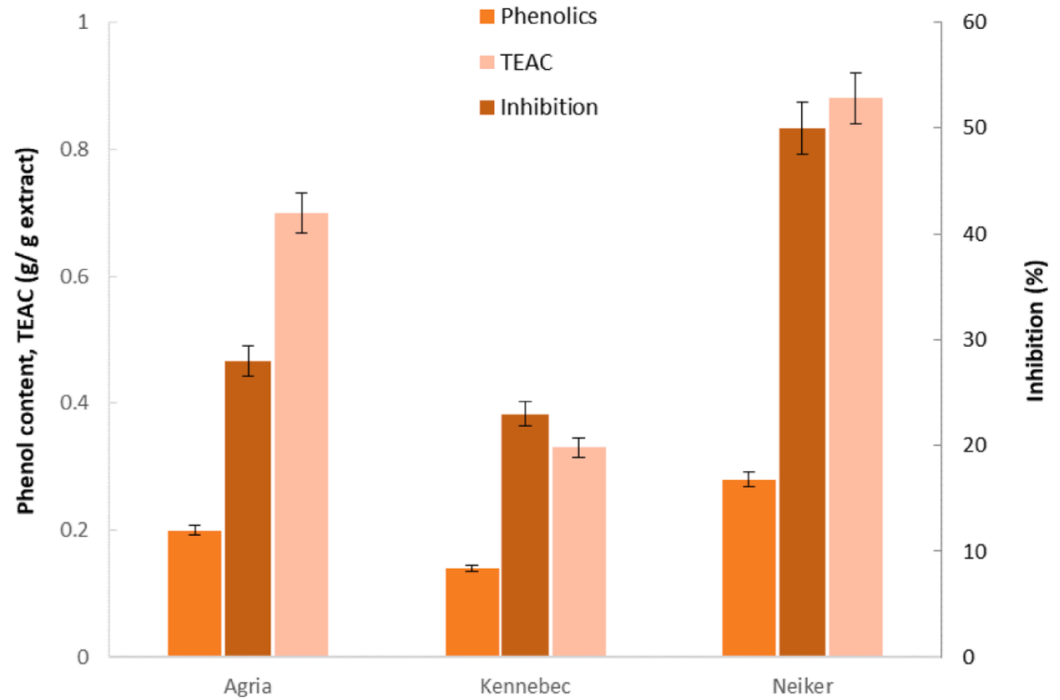

(c)

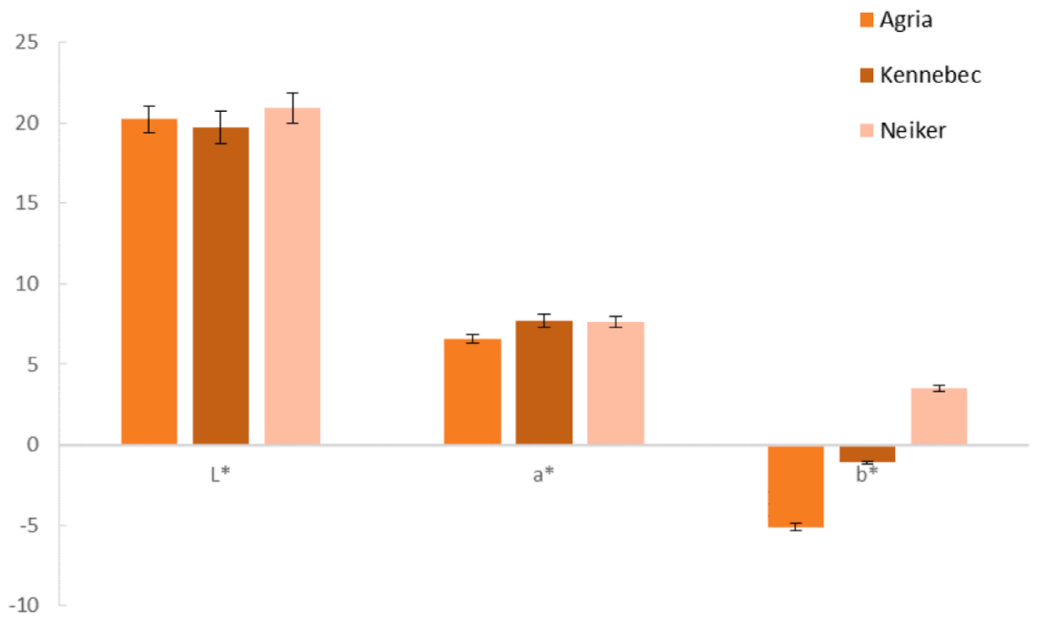




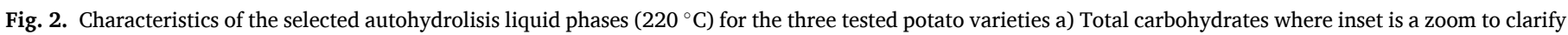

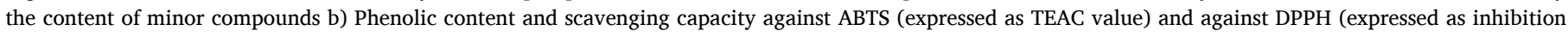
percentage) and c) colour.

moduli, holding a peak about 60 C. These tendencies have been commonly found for native starches (Xing et al., 2018), with gelatinisation temperature for native potato starches around 57-58 C. The inflection point was shifted to higher temperatures with increasing temperature (almost 10 C) as reported elsewhere (Witczak et al., 2015; Torres et al., 2018). The sweep time after heating step (Fig. 3b) clearly showed the high stability of tested samples, immediately achieving stable viscoelastic behaviour (i.e. G' $>G^{\prime \prime}$ with constant values). The required time to hold stable moduli can dramatically vary depending on the biopolymer-based tested matrix (Nunes et al., 2006). This is critically relevant for potato starches, which are commonly less thermostable than other commonly used starches (Mandala and Palagou, 2003;

(a)

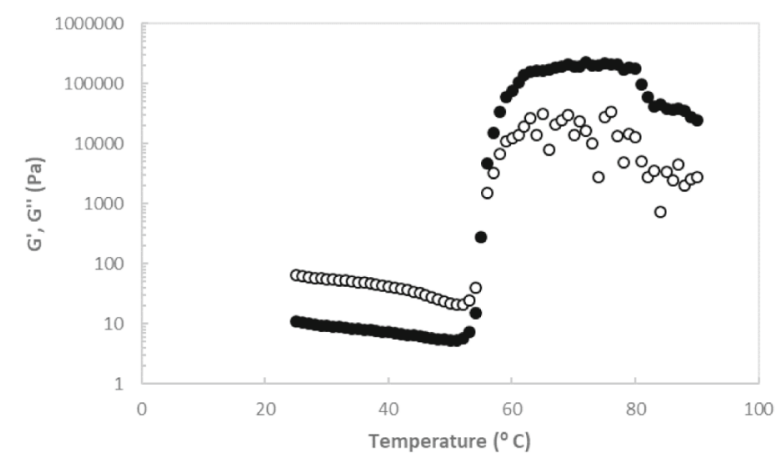

(c)

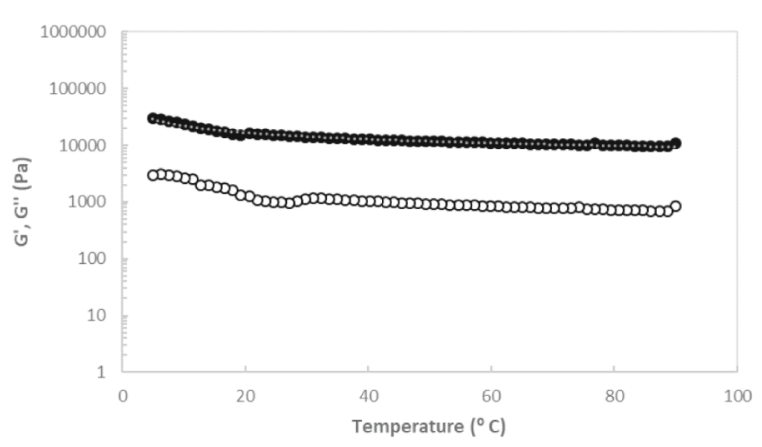

(e)

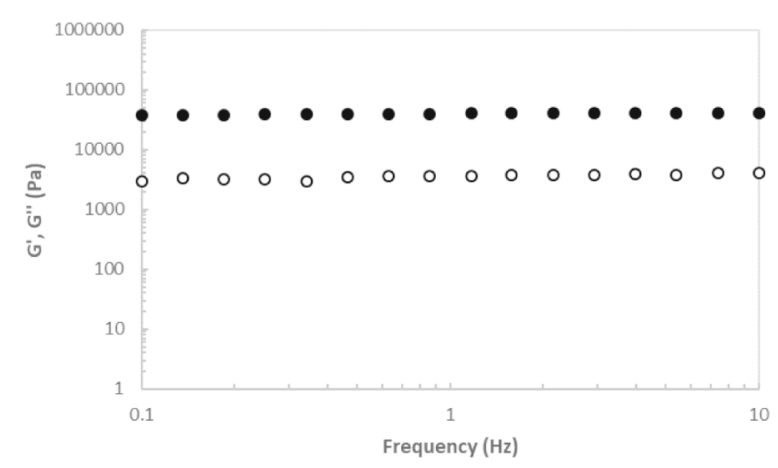

Torres et al., 2018). During the cooling step (Fig. 3c), the values of $\mathrm{G}^{\prime}$ and $\mathrm{G}^{\prime \prime}$ slightly rose, indicating a moderate reinforcement of the hydrogel structure. This is consistent with the behaviour found for other starchy (Torres et al., 2019; Nunes et al., 2006) and non-starchy (Alvarez and Canet, 2013) gelled systems. The maturation profiles of developed hydrogels (Fig. 3d) indicated that the dynamic hydrogel network equilibration was instantaneously achieved with steady values for G' $\left(\sim 3.110^{5} \mathrm{~Pa}\right)$ and G' $\left(\sim 2.510^{3} \mathrm{~Pa}\right)$. These maturation times were lower than those reported for other concentrated gels $(<40 \% \mathrm{w} / \mathrm{w})$ formulated with native starches from different natural resources (Orford et al., 1987). The mechanical spectrum in terms of viscous and elastic moduli evolution with frequency of above hydrogel is presented in Fig. 3e. In all (b)

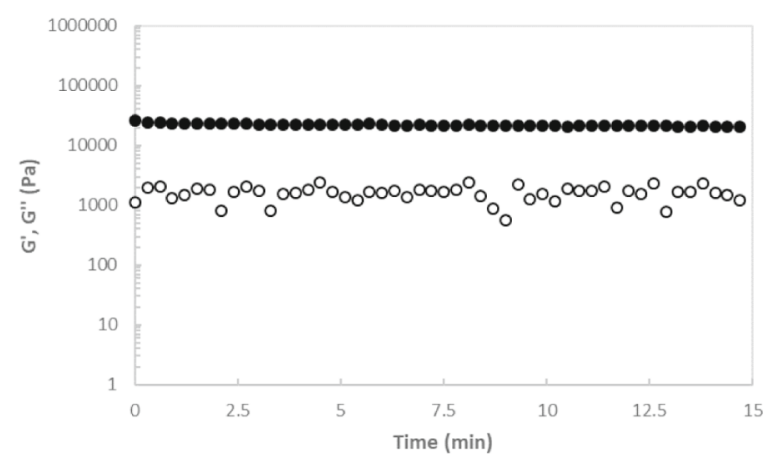

(d)

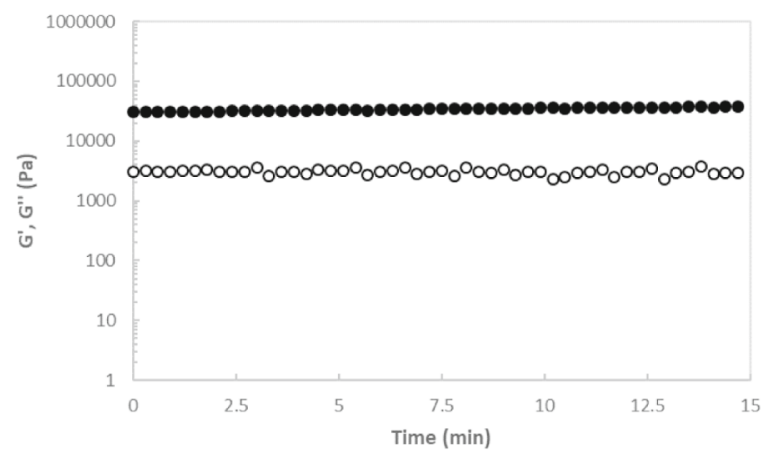

Fig. 3. Thermorheological profile representative of tested systems prepared with Agria starch (15\%, 90 C): (a) temperature profiles on heating (25-90 C at 1 C/ min), (b) time sweep $\left(90 \mathrm{C}\right.$ ), (c) cooling (90-5 C at 1 C/min), (d) time sweep $(5 \mathrm{C})$, (e) frequency sweep (25 C). Symbols: closed (elastic modulus, $\left.\mathrm{G}^{\prime}\right)$, open (viscous modulus, $\mathrm{G}^{\prime \prime}$ ). 
cases, a typical gel spectrum was observed, with $\mathrm{G}^{\prime}>\mathrm{G}^{\prime \prime}$ and both moduli frequency independent (Torres et al., 2018).

Further insight of concentrated starch hydrogels behaviour is essential in order to improve the processing conditions in multicomponent systems. Fig. 4 shows a general overview on the strength ( $\mathrm{G}^{\prime}$ gel, $1 \mathrm{~Hz}$ ) of the hydrogels prepared with Agria starch when compared with those from commercial starch, as representative of tested systems. In all cases, extracted starch presented higher (between 3 and 5 times) viscoelastic features to its commercial counterpart, although following similar tendencies. It was clearly observed that $\mathrm{G}^{\prime}$ gel increased with increasing concentration or gelling temperature. The enhancement of viscoelastic properties with either the rise in starch content or gelling temperature is consistent with the results previously reported for other starches with similar amylose content (Nunes et al., 2006). It should be noted that among the tested varieties, hydrogels formulated with starch from Agria exhibited the best mechanical properties, followed closely by Kennebec. Even though, the starch of Neiker also led to hydrogels with adequate mechanical properties. Viscoelastic values for tested hydrogels are in the range of those reported for several potential applications from the food (e.g. commercial savoury/sweet gelled systems) to the non-food (e.g. cosmetics and health personal care products) fields (Nunes et al., 2006; BeMiller and Whistler, 2009). Studied hydrogels also exhibited viscoelastic features consistent with those reported for gelled formulations employed in biofilms-based matrices (Peterson et al., 2015).

The incorporation of bioactives from Neiker variety allowed the extension of the possibilities of application, by obtaining weaker hydrogels (between 3 and 20 times) with suitable mechanical properties for different applications (Fig. 4). Note here that longer maturation time (below $12 \mathrm{~min}$ ) was required for hydrogels prepared using as solvent the selected liquid autohydrolysis fractions. This kind of weaker functional hydrogels can be highly valuable as basis of preparations for target population with particular requirements, as gelled matrices for baby or elder food (Alvarez and Canet, 2013). Moreover, above hydrogels could be attractive alternatives for the development of functional biofilms incorporated with glycerol, based on the results previously found for other biopolymer-based biofilms (Moreira et al., 2011; Larotonda et al., 2016) and evaluated in a parallel work (Torres et al., 2019).

\subsubsection{Textural features}

Table 4 summarises the textural properties of formulated hydrogels. In all cases, absence of syneresis was found for the analysed period (two weeks). As expected, firmness significantly increased with increasing starch concentration or gelling temperature. Hydrogels from commercial and extracted starches presented the same tendency, although notably higher values were identified in those prepared from extracted starches. This behaviour suggests to be related to the largest total starch content in extracted starches. The magnitude of this parameter was notably higher than those previously reported for commercial potato starches and in the range of those roasted starches (Torres et al., 2018). The firmness of tested hydrogels varied in a wide range, being comparable with those values reported for hydrogels formulated with mixtures of gelatine (8\%, w/w)-corn starch (5\%, w/w) (Marfil et al., 2012), but also with those prepared with achira starch at much higher starch content $(80 \% \mathrm{w} / \mathrm{w})$ (Fonseca-Florido et al., 2017). Adhesiveness values significantly increased with increasing gelatinisation temperature for hydrogels prepared at starch concentration of $15 \%$, whereas the reverse trend was observed above $20 \%$. Concerning cohesiveness values, this parameter did not present significant differences with gelatinisation temperatures at starch content below $20 \%$, whereas a decreasing trend was noticed at the highest starch content. Overall, all functional hydrogels provided lower values in all assessed textural parameters when compared with those prepared in the absence of bioactive liquors.

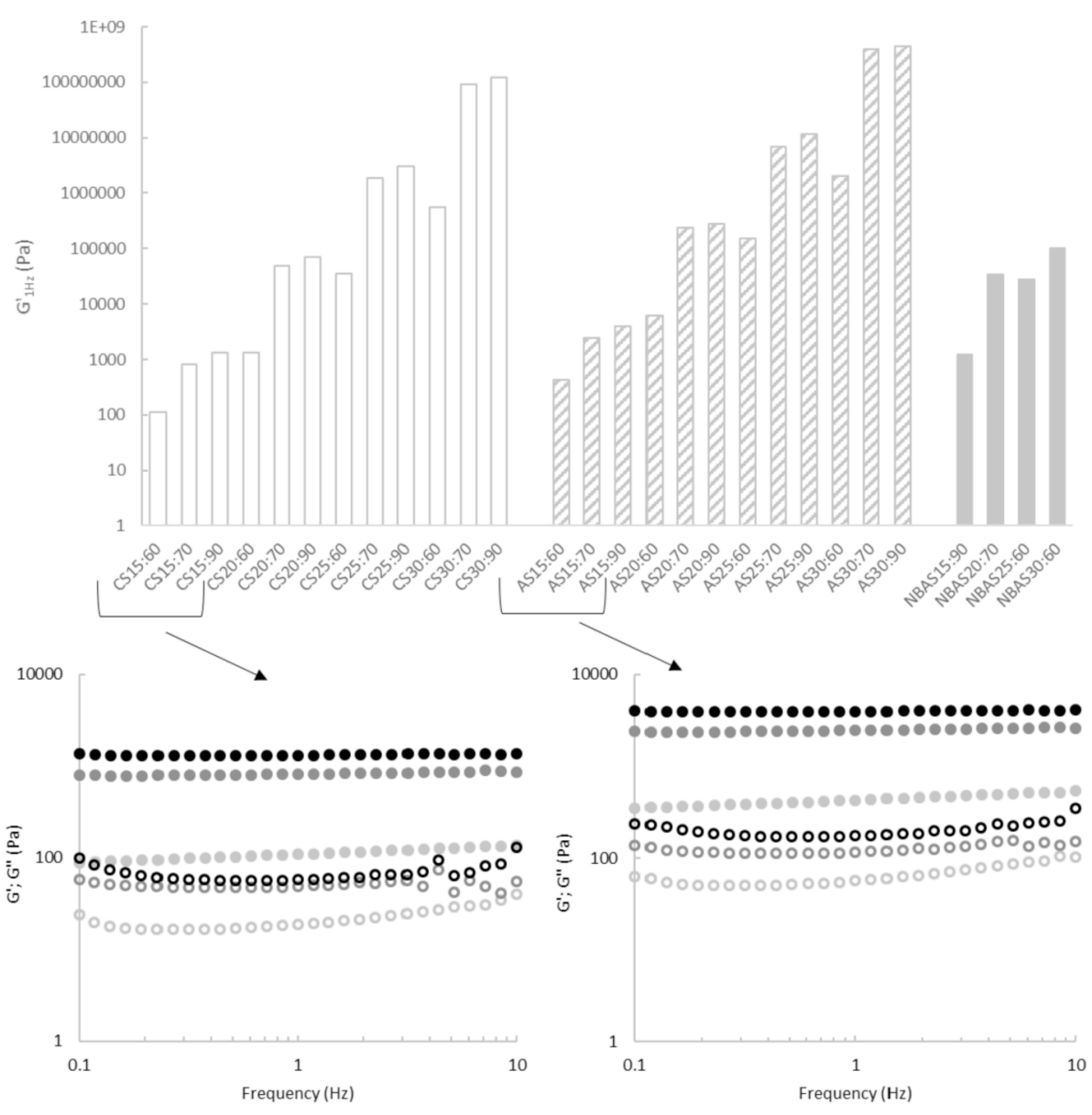

Fig. 4. Comparative of viscoelastic properties throughout $\mathrm{G}^{\prime}{ }_{1 \mathrm{~Hz}}$ from the mechanical spectra for tested hydrogels, including those prepared with bioactive fractions. Two sets of representative mechanical spectra are presented for clarity (left - CS, right - AS). Symbols: white bars (CS, hydrogels from commercial starch), striped bars (AS, hydrogels from Agria starch) and grey bars (NBAS, hydrogels from Agria starch and Neiker bioactives), black circles (CS15:60, AS15:60), dark grey circles (CS15:70, AS15:70), light grey circles (CS15:90, AS15:90), closed (elastic modulus, $\mathrm{G}^{\prime}$ ), open (viscous modulus, $\left.\mathrm{G}^{\prime \prime}\right)$. 
Table 4

Texture of hydrogels formulated with commercial starch (CS) and extracted from Agria variety (AS). Selected functional hydrogels (NBAS) prepared using as solvent liquid autohydrolysis fraction of Neiker variety.

\begin{tabular}{|c|c|c|c|c|c|c|}
\hline \multirow{2}{*}{$\begin{array}{l}\text { Hydrogels } \\
\text { CS15:60 }\end{array}$} & \multicolumn{2}{|c|}{ Firmness (N) } & \multicolumn{2}{|c|}{ Adhesiveness (N.s) } & \multicolumn{2}{|c|}{ Cohesiveness ( ) } \\
\hline & 0.04 & $0.01^{\mathrm{p}}$ & 0.08 & $0.01^{\tilde{\mathrm{n}}}$ & 0.38 & $0.02^{\mathrm{d}}$ \\
\hline CS15:70 & 0.02 & $0.01^{\mathrm{p}}$ & 0.04 & 0.01 & 0.39 & $0.09^{d}$ \\
\hline CS15:90 & 0.45 & $0.02^{\mathrm{m}}$ & 0.45 & $0.03^{\mathrm{k}}$ & 0.44 & $0.01^{\mathrm{d}}$ \\
\hline CS20:60 & 0.57 & $0.03^{11}$ & 0.98 & $0.11^{g}$ & 0.38 & $0.03^{\mathrm{d}}$ \\
\hline CS20:70 & 0.87 & $0.04^{\mathrm{k}}$ & 0.75 & $0.02^{\mathrm{h}}$ & 0.39 & $0.05^{\mathrm{d}}$ \\
\hline CS20:90 & 1.6 & $0.1^{\mathrm{j}}$ & 0.28 & $0.06^{1,11}$ & 0.38 & $0.06^{\mathrm{d}}$ \\
\hline CS25:60 & 2.4 & $0.1^{\mathrm{i}}$ & 2.4 & $0.1^{\mathrm{e}}$ & 0.35 & $0.02^{\mathrm{d}, \mathrm{e}}$ \\
\hline CS25:70 & 2.4 & $0.2^{\mathrm{i}}$ & 2.3 & $0.1^{\mathrm{e}}$ & 0.30 & $0.03^{\mathrm{e}}$ \\
\hline CS25:90 & 4.7 & $0.4^{g}$ & 1.8 & $0.2^{\mathrm{f}}$ & 0.27 & $0.01^{\mathrm{e}}$ \\
\hline CS30:60 & 3.8 & $0.2^{\mathrm{h}}$ & 0.89 & $0.05^{\mathrm{g}}$ & 0.07 & $0.03^{g}$ \\
\hline CS30:70 & 10.8 & $0.9^{\mathrm{e}}$ & 0.61 & $0.09^{\mathrm{i}}$ & 0.10 & $0.07^{g}$ \\
\hline CS30:90 & 12.5 & $1.7^{\mathrm{d}}$ & 0.18 & $0.04^{\mathrm{m}}$ & 0.01 & $0.01^{\mathrm{h}}$ \\
\hline AS15:60 & 0.13 & $0.1^{\tilde{\mathrm{n}}}$ & 0.25 & $0.02^{11}$ & 1.1 & $0.1^{\mathrm{a}}$ \\
\hline AS15:70 & 0.08 & 0.01 & 0.12 & $0.2^{\mathrm{n}}$ & 1.2 & $0.2^{\mathrm{a}}$ \\
\hline AS15:90 & 1.4 & $0.1^{\mathrm{j}}$ & 1.7 & $0.2^{\mathrm{f}}$ & 1.3 & $0.1^{\mathrm{a}}$ \\
\hline AS20:60 & 1.8 & $0.2^{\mathrm{j}}$ & 3.2 & $0.2^{\mathrm{d}}$ & 1.1 & $0.3^{\mathrm{a}}$ \\
\hline AS20:70 & 2.5 & $0.3^{\mathrm{i}}$ & 2.4 & $0.2^{\mathrm{e}}$ & 1.2 & $0.4^{\mathrm{a}}$ \\
\hline AS20:90 & 4.9 & $0.1^{g}$ & 0.90 & $0.1^{g}$ & 1.1 & $0.2^{\mathrm{a}}$ \\
\hline AS25:60 & 7.1 & $0.1^{\mathrm{f}}$ & 7.4 & $0.1^{\mathrm{a}}$ & 1.0 & $0.3^{\mathrm{a}}$ \\
\hline AS25:70 & 7.3 & $0.1^{\mathrm{f}}$ & 6.9 & $0.4^{\mathrm{b}}$ & 0.90 & $0.02^{\mathrm{b}}$ \\
\hline AS25:90 & 14.3 & $0.2^{\mathrm{c}}$ & 5.6 & $0.1^{\mathrm{c}}$ & 0.81 & $0.01^{\mathrm{c}}$ \\
\hline AS30:60 & 11.1 & $0.3^{\mathrm{d}, \mathrm{e}}$ & 2.8 & $0.3^{\mathrm{d}}$ & 0.21 & $0.04^{f}$ \\
\hline AS30:70 & 32.2 & $0.6^{\mathrm{b}}$ & 1.9 & $0.2^{\mathrm{f}}$ & 0.30 & $0.02^{\mathrm{e}}$ \\
\hline AS30:90 & 37.5 & $1.2^{\mathrm{a}}$ & 0.56 & $0.03^{\mathrm{j}}$ & 0.03 & $0.01^{\mathrm{h}}$ \\
\hline NBAS15:90 & 0.20 & $0.01^{\mathrm{n}}$ & 0.34 & $0.02^{1}$ & 0.40 & $0.02^{\mathrm{d}}$ \\
\hline NBAS20:70 & 0.65 & $0.03^{1}$ & 0.18 & $0.04^{\mathrm{m}}$ & 0.26 & $0.02^{\mathrm{e}}$ \\
\hline NBAS25:60 & 1.7 & $0.2^{\mathrm{j}}$ & 2.0 & $0.2^{\mathrm{e}, \mathrm{f}}$ & 0.21 & $0.01^{\mathrm{f}}$ \\
\hline NBAS30:60 & 2.9 & $0.3^{\mathrm{i}}$ & 0.68 & $0.02^{\mathrm{i}}$ & 0.03 & $0.01^{\mathrm{h}}$ \\
\hline
\end{tabular}

Data are presented as mean standard deviation. Data values in a column with different superscript letters are significantly different at the $p \quad 0.05$ level. Note that the hydrogels are labelled with the concentration followed by the temperature at which they were prepared.

The broad range of adhesiveness and/or cohesiveness values found in this study are relevant for the product development, allowing to extent the pallet of the potential final applications depending on the selected processing conditions. An increase in these parameters is essential in the processing of a number of different products such as sweet/savoury gelled matrices, biofilms or glues (Nunes et al., 2006; Genovese et al., 2010). The macrostructural texture outcomes obtained here were in well harmony with those aforementioned from the microstructural rheological results.

Overall, the largest total starch content of extracted starches, compared to the commercial counterpart used as control, allowed decreasing the required starch doses in the prepared formulations. It was also possible to reduce the maturation time during the hydrogels formation when compared with other starchy gelled systems (Nunes et al., 2006; Torres et al., 2018). Another advantage was the absence of syneresis of the developed hydrogels with extracted starches, which is of great relevance from the point of view of the application.

\section{Conclusions}

To conclude, it should be indicated that low-sized or irregular shape discarded potatoes properly processed have a great potential for food and non-food applications. Each tested potato variety exhibited specific properties, which make it suitable for its revalorisation focused on different final products. Flesh from Agria is a good source of high quality starch and peels from Neiker are a nice source of bioactive compounds, whereas Kennebec is a good source of carbohydrates and minerals. The feasibility of preparing functional hydrogels with attractive mechanical properties provides new routes for the integral valorisation of the discarded potatoes. The proposed hydrogels pallet means a relevant increase in potential end-uses with healthy properties, with the consequent added value from the economic, social, industrial and environmental point of view.

\section{Acknowledgements}

The authors thank financial support (INOU 18-07) to the Diputacion Provincial de Ourense and the Universidad de Vigo. We also acknowledge to the Instituto Ourensan de Desenvolvemento Economico (INORDE), who kindly provided local discarded potatoes. M.D.T. thanks Spanish Ministry of Economy and Competitiveness for her postdoctoral grant (IJCI-2016-27535).

\section{References}

AACC, 2010. Approved Methods of Analysis, eleventh ed. American Association of Cereal Chemistry, Eagan, MN.

Ahmed, S., Zhou, X., Pang, Y., Jin, L., Bao, J., 2018. Improving starch-related traits in potato crops: achievements and future challenges. Starch Staerke 70, 1700113.

Alvarez, M.D., Canet, W., 2013. Dynamic viscoelastic behaviour of vegetable based infant purees. J. Texture Stud. 44, 205-224.

AOAC, 2000. Official Methods of Analysis. Association of Official Analytical Chemistry, Washington, USA.

ASAE Standards, 1995. S319.2: Methods for determining and expressing fineness of feed materials by sieving. American Society of Agricultural Engineers, Michigan, USA.

Bashir, K., Swer, T.L., Prakash, K.S., Aggarwal, M., 2017. Physico-chemical and functional properties of gamma irradiated whole wheat flour and starch. LWT- Food Sci. Technol. 76, 131-139.

BeMiller, J., Whistler, R., 2009. Starch: Chemistry and Technology, third ed. Elsevier, New York, USA.

Brunner, G., 2009. Near critical and supercritical water (47). Part I. Hydrolytic and hydrothermal processes. J. Supercrit. Fluids 47, 373-381.

Bzducha-Wrobel, A., Błażejak, S., Molenda, M., Reczek, L., 2015. Biosynthesis of $\beta(1,3)$ / $(1,6)$-glucans of cellwall of the yeast Candida utilis ATCC 9950 strains in the culture media supplemented with deproteinated potato juice water and glycerol. Eur. Food Res. Technol. 240, 1023-1034.

de Albuquerque, T.M.R., Sampaio, K.B., de Souza, E.L., 2019. Sweet potato roots: unrevealing an old food as a source of health promoting bioactive compounds - a review. Trends Food Sci. Technol. 85, 277-286.

De Gisi, S., Lofrano, G., Grassi, M., Notarnicola, M., 2016. Characteristics and adsorption capacities of low-cost sorbents for wastewater treatment: a review. Sustain. Mater. Technol. 9, 10-40.

Dupuis, J.H., Liu, Q., 2019. Potato starch: a review of physicochemical, functional and nutritional properties. Am. J. Potato Res. https://doi.org/10.1007/s12230-01809696-2.

FAOSTAT, 2017. Statistics division of food and agriculture organization of the United Nations. Available from: http://www.fao.org/faostat.

Florez-Fernandez, N., Torres, M.D., Gonzalez-Muñoz, M.J., Domínguez, H., 2019. Recovery of bioactive and gelling extracts from edible brown seaweed Laminaria ochroleuca by non-isothermal autohydrolysis. Food Chem. 277, 353-361.

Fonseca-Florido, H.A., Gomez-Aldapa, C.A., Velazquez, G., Hernandez-Hernandez, E., Mata-Padilla, J.M., Solís-Rosales, S.G., Mendez-Montealvo, G., 2017. Gelling of amaranth and achira starch blends in excess and limited water. LWT - Food Sci. Technol. (Lebensmittel-Wissenschaft -Technol.) 81, 265-273.

Friedman, M., Kozukue, N., Kim, H.J., Choi, S.H., Mizunod, M., 2017. Glycoalkaloid, phenolic, and flavonoid content and antioxidative activities of conventional nonorganic and organic potato peel powders from commercial gold, red, and Russet potatoes. J. Food Compos. Anal. 62, 69-75.

Genovese, D.B., Ye, A., Singh, H., 2010. High methoxyl pectin/apple particles composite gels: effect of particle size and particle concentration on mechanical properties and gel structure. J. Texture Stud. 41, 171-189.

Gonzalez, N., Otero, A., Conde, E., Falque, E., Moure, A., Domínguez, H., 2017. Extraction of phenolics from broom branches using green technologies. J. Chem. Technol. Biotechnol. 92 (6), 1345-1352.

Gientka, I., Aleksandrzak-Piekarczyk, T., Bzducha-Wrobel, A., Synowiec, A., Błażejak, S., 2019. Deproteinated potato wastewater as a sustainable Nitrogen source in Trichosporon domesticum yeast lipids biosynthesis-a Concept of valorization of wastewater from starch industry. Potato Res. https://doi.org/10.1007/s11540-0189408-x.

Grudzinska, M., Czerko, Z., Zarzynska, K., Borowska-Komenda, M., 2016. Bioactive compounds in potato tubers: effects of farming system, cooking method, and flesh color. PLoS One 11 (5), e0153980.

Jonathan, G., Karim, A., 2016. 3D printing in pharmaceutics: a new tool for designing customized drug delivery systems. Int. J. Pharm. 499, 376-394.

Larotonda, F.D.S., Torres, M.D., Gonçalves, M.P., Sereno, A.M., Hilliou, L., 2016. Hybrid carrageenan-based formulations for edible film preparation: benchmarking with kappa carrageenan. J. Appl. Polym. Sci. 133, 42263.

Lefatle, M.C., John, M.J., 2018. Mechanical, rheological and viscoelastic properties of polysaccharide and protein based aerogels. RSC Green Chem. 58, 177-200.

Liu, J., Willfor, S., Xu, Ch, 2015. A review of bioactive plant polysaccharides: biological activities, functionalization, and biomedical applications. Bioact. Carbohydr. Diet. Fibre 5, 31-61. 
Mandala, L.G., Palagou, E.D., 2003. Effect of preparation conditions and starch xanthan concentration on gelation process of potato starch systems. Int. J. Food Prop. 6, $311-328$.

Moreira, R., Chenlo, F., Torres, M.D., Silva, C., Prieto, D.M., Sousa, A.M.M., Hilliou, L., Gonçalves, M.P., 2011. Drying kinetics of biofilms obtained from chestnut starch and carrageenan with and without Glycerol. Dry. Technol. 29, 1058-1065.

Marfil, P.H.M., Anhê, A.C.B.M., Telis, V.R.N., 2012. Texture and microstructure of gelatin/corn starch-based gummy confections. Food Biophys. 7 (3), 236-243.

Navarre, D.A., Brown, C.R., Sathuvalli, V.R., 2019. Potato vitamins, minerals and phytonutrients from a plant biology perspective. Am. J. Potato Res. https://doi.org/ 10.1007/s12230-018-09703-6.

Nor Nadiha, M.Z., Fazilah, A., Bhat, R., Karim, A.A., 2010. Comparative susceptibilities of sago, potato and corn starches to alkali treatment. Food Chem. 121, 1053-1059.

Nunes, M.C., Raymundo, A., Sousa, I., 2006. Rheological behaviour and microstructure of pea protein/ $/$ - carrageenan/starch gels with different setting conditions. Food Hydrocolloids 20, 106-113.

Nazarian-Firouzabadi, F., Visser, R.G.F., 2017. Potato starch synthases: functions and relationships. Biochem. Biophys. Rep. 10, 7-16.

Orford, P.D., Ring, S.G., Mervyn, V.C., Miles, M.J., Morris, V.J., 1987. The effect of concentration and botanical source on the gelation and retrogradation of starch. J. Sci. Food Agric. 39, 169-177.

Pathak, P.D., Mandavgane, S.A., Puranik, N.M., Jambhulkar, S.J., Kulkarni, B.D., 2018. Valorization of potato peel: a biorefinery approach. J. Crit. Rev. Biotechnol. 38, 218-230.

Peksa, A., Lubowska, G., Anilowski, K., Lisinska, G., Rytel, E., 2009. Changes of glycoalkaloids and nitrate contents in potatoes during chip processing. J. Food Chem. 97, 151-156.

Peterson, B.W., He, Y., Ren, Y., Zerdoum, A., Libera, M.R., Sharma, P.K., van Winkelhoff, A.J., Neut, D., Stoodley, P., van der Mei, H.C., Busscher, H.J., 2015 Viscoelasticity of biofilms and their recalcitrance to mechanical and chemical challenges. Microbiol. Rev. 39, 234-245, 2015.

Priedniece, V., Spalvins, K., Ivanovs, K., Pubule, J., Blumberga, D., 2017. Bioproducts from potatoes. A review. Environ. Clim. Technol. 21, 18-27.

Re, R., Pellegrini, N., Proteggente, A., Pannala, A., Yang, M., Rice-Evans, C., 1999. Antioxidant activity applying an improved ABTS radical cation decolorization assay. Free Radic. Biol. Med. 26, 1231-1237.
Reyniers, S., De Brier, N., Matthijs, S., Brijs, K., Delcour, J.A., 2018. Impact of physical and enzymatic cell wall opening on the release of pre-gelatinized starch and viscosity forming potential of potato flakes. Carbohydr. Polym. 194, 401-410.

Robertson, T.M., Alzaabi, A.Z., Robertson, M.D., Fielding, B.A., 2018. Starchy carbohydrates in a healthy diet: the role of the humble potato. Nutrients 10, 1764.

Seijo-Rodríguez, A., Escuredo, O., Rodríguez-Flores, M.S., Seijo-Coello, M.C., 2018. Assessment of antioxidant potential of potato varieties and the relationship to chemical and colorimetric measurements. Am. J. Potato Res. 95 (1), 71-78.

Sepelev, I., Galoburda, R., 2015. Industrial potato peel waste application in food production: a Review. Res. Rural Develop. 1, 130-1362.

Silva, Norma, Chaidez-Quiroz, Cristobal, Lopez, Osvaldo, Ruiz-Cruz, Saúl, Lopez, Marco, Lizette, Del Toro, Enrique, Marquez Rios, Jose, Ornelas-Paz, 2016. Phenolic compounds of potato peel extracts: their antioxidant activity and protection against human enteric viruses. J. Microbiol. Biotechnol. 27 https://doi.org/10.4014/ jmb.1606.06007.

Singleton, V.L., Rossi, J.A., 1965. Colorimetry of total phenolics with phosphomolybdicphosphotungstic acid reagents. Am. J. Enol. Vitic. 16, 144-158.

Torres, M.D., Fradinho, P., Rodríguez, P., Santos, V., Falque, E., Domínguez, H., 2019. Formulacions xelificantes a base de extractos de patacas de descarte e augas termais da provincia de Ourense para produtos de interese industrial. Proxectos da Diputacion de Ourense, INOU18. [Gelifying formulations based on extracts of discarding potatoes and thermal waters of the province of Ourense for products of industrial interest. Projects of the Diputacion de Ourense, INOU18].

Torres, M.D., Chenlo, F., Moreira, R., 2018. Rheological effect of gelatinisation using different temperature-time conditions on potato starch dispersions: mechanical characterisation of the obtained gels. Food Bioprocess Technol. 11, 132-140.

Witczak, M., Ziobro, R., Juszczak, L., Korus, J., 2015. Starch and starch derivatives in gluten-free systems - a review. J. Cereal Sci. 67, 46-57.

Wu, D., 2016. Recycle technology for waste residue in potato starch processing: a review (2016). Procedia Environ. Sci. 31, 108-112.

Xing, J., Jie, D., Li, L., Wang, J., Adhikari, B., 2018. Temperature thresholds and timetemperature dependence of gelatinization for heat-moisture treated corn starch. J. Food Eng. 217, 43-49. 